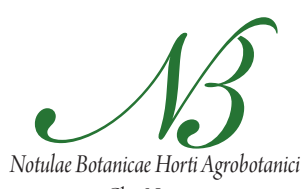

Cluj-Napoca

\title{
Effect of Chlorocholine Chloride on Chlorophyll, Photosynthesis, Soluble Sugar and Flavonoids of Ginkgo biloba
}

\author{
Weiwei ZHANG ${ }^{1,2}$, Feng XU ${ }^{3}$, Hua $\mathrm{CHENG}^{2}$, Linling $\mathrm{LI}^{2}$, Fuliang $\mathrm{CAO}^{1}$, Shuiyuan $\mathrm{CHENG}^{2 *}$ \\ ${ }^{1}$ Nanjing Forestry University, Forest Resources and Environment Institute, Nanjing, 210037, China \\ ${ }^{2}$ Huanggang Normal University, Hubei Key Laboratory of Economic Forest Germplasm Improvement and Resources \\ Comprehensive Utilization, Huanggang, Hubei 438000, China; s_y_cheng@sina.com ("corresponding author) \\ ${ }^{3}$ Yangtze University, College of Horticulture and Gardening, Jingzhou, 434025, China
}

\begin{abstract}
The flavonoids content determines the quality characteristics of Ginkgo biloba extract that could be increased by using of plant growth regulators. The objective of study was to investigate the effect of chlorocholine chloride (CCC), an anti-gibberellin growth retardant, on photosynthesis, chlorophyll, soluble sugar, total amino acids and phenylalanine contents, flavonoid accumulation, and flavonoids enzyme activity in $G$. biloba leaves. The ginkgo seedlings were grown in the greenhouse conditions with foliar

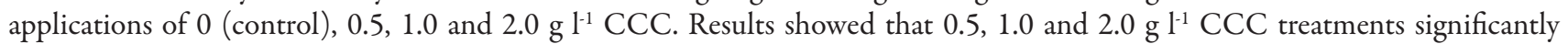
increased photosynthetic rates of leaves, the contents of chlorophyll, soluble sugar, total amino acids and phenylalnine in ginkgo leaves. Total polyphenols, flavonoids, anthocyanins content, phenylalanine ammonia-lyase (PAL), chalcone synthase (CHS) and chalcone isomerase (CHI) activities were all significantly increased by 1.0 and $2.0 \mathrm{~g} \mathrm{l}^{-1} \mathrm{CCC}$ treatments. Foliar treatment with CCC therefore might be a useful means of improving pharmacological properties of $G$. biloba leaves.
\end{abstract}

Keywords: chlorocholine chloride, chlorophyll, flavonoids, Ginkgo biloba, photosynthesis, soluble sugar,

\section{Introduction}

The flavonoids, one kind of polyphenolic compounds, have a broad spectrum of action in plants. They protect against UV-B radiation and pathogen attack, act as attractants for pollinators, act as signal molecules for initiating plant-microbe symbiotic associations (Winkel-Shirley, 2002) and have been used as colorants, and for allelopathy (Hossain et al., 2009). The studies on flavonoids in G. biloba had been more and more popular due to their antioxidative constituent that beneficial for human health. The flavonoids extracted from G. biloba leaves showed antioxidant activity and protection against the damages caused by free radicals, which play an important role in many diseases, such as cerebral hypoxia, cardiovascular disease and cancer (Ding et al., 2009; Iwashita et al., 2000; Kawaii et al., 1999; Sachin et al., 2000). Standardized preparations of G. biloba, Egb761, contain 24\% flavonoids, which have several pharmaceutical properties for human health (van Beek, 2002). In G. biloba, flavonoids located primarily in the leaf are important determinants of its pharmacological properties and determine the quality characteristics of ginkgo tea or extract. Therefore, much interest is currently focusing on increasing the medicinal value of ginkgo leaves by increasing their flavonoid contents. In vivo experiments on ginkgo leaves indicated that externally supplied CCC,
$\mathrm{ABA}$, ethephon, and metal ions could increase flavonoid contents (Cheng et al., 2004; Wang et al., 2007).

Chlorocholine chloride (CCC, 2-chloroethyltrimethylammonium chloride) is an antigibberellin growth retardant, with its mechanism based on the restraint of gibberellin biosynthesis in plant tissues (Wang and Xiao, 2009). It is well known that CCC induces changes in the growth rate of grasses and the morphogenesis of potato plants cultured in vitro. CCC recently has been widely used in potato production to increase yield and quality. Application of CCC causes an increase in dry matter accumulation in sweet potato tubers (Wang et al., 2009). CCC might induce higher tuber production by causing an increase in chlorophyll content and photosynthesis (Sharma et al., 1998a; Wang et al., 2009). In addition, CCC treatment can enhance plant nutrient uptake from soil, improve water balance and protein synthesis in growing organs (Grossmann, 1990; Wang et al., 2010). Furthermore, CCC was also found to promote anthocyanin synthesis in red cabbage and spiderwort leaves (Grebinskii and Khmil, 1980). Anthocyanin biosynthesis could be enhanced by feeding of precursors of both the moieties namely, phenylalanine, trans-cinnamic acid, glucose, sucrose and acetate (Guruprasad and Laloraya, 1980; Jain and Guruprasad, 1989). CCC also causes accumulation of carbohydrates in the tissues of wheat plants (Pikush, 1974). 
98

Therefore, CCC application might be a promising practice for improving the secondary metabolite production in ginkgo leaves, such as flavonoids (Cheng et al., 2009). A study by Cheng et al. (2011) showed that CCC treatment could promote flavonoid accumulation in ginkgo leaves. However, the underlying physiological mechanisms of CCC treatment enhancing the flavonoids content have not yet been elucidated. In this study, the effects of foliar application of different concentrations of CCC on photosynthesis, contents of chlorophyll, carbohydrate and activities of enzymes involved in flavonoid were investigated. Furthermore, total polyphenols, flavonoids, and anthocyanins accumulation in ginkgo leaves, which could be promoted by application of CCC were also determined. The objective of the present study was to evaluate the physiological action and to provide a theoretical basis of CCC application for high-yield flavonoid content in ginkgo leaves.

\section{Materials and methods}

\section{Plant materials and CCC treatments}

Three-years seedlings of G. biloba cv. 'Jiafoshou' were sown in the pots $(25 \mathrm{~cm}$ diameter, $40 \mathrm{~cm}$ height, 1 plant/ pot) filled with sandy soil (sand: humus soil 1:2). All seedlings were placed in a greenhouse with $12 \mathrm{~h}$ photoperiod $\left(25^{\circ} \mathrm{C}\right.$; day/night, $\left.500 \mu \mathrm{mol} \mathrm{m}^{-2} \mathrm{~s}^{-1}\right)$ at $60-70 \% \mathrm{RH}$, and irrigated daily with $1 / 2$ Hoagland solution. After the fourth leaves were fully expanded, all seedlings were treated by foliar sprayed with aqueous solutions of CCC (containing $0.01 \%$ Tween $20, \mathrm{pH} 5.8$ ) at four concentrations of 0 (the control), $0.5,1.0$, and $2.0 \mathrm{~g} \mathrm{l}^{-1}$. Twenty $\mathrm{mL}$ of solution was applied once/month for three months. Six replications (9 plants/replication) were used per treatment and sample pooled for each determination. All the measurements were made 4 months after the initial application of CCC.

Measurement of photosynthetic rates, Chlorophyll $a+b$, soluble sugar, total amino acids and phenylalnine contents

The photosynthetic parameters were determined on the fifth leaf using a LiCor-6400 portable photosynthesis system (LiCor, U.S.A.) according to the instruction manual. Measurement periods were in the morning from 8:00 to 11:00 am when leaves of G. biloba were under a light intensity of $1000 \mu \mathrm{mol} \cdot \mathrm{m}^{-2} \cdot \mathrm{s}^{-1}$ and humidity of $60 \%$ (Adamski et al., 2011).

Chlorophyll $\mathrm{a}+\mathrm{b}$ content was determined on fully expanded leaves. Leaf material was homogenized in cold $\left(4^{\circ} \mathrm{C}\right)$ aqueous $80 \%(\mathrm{v} / \mathrm{v})$ acetone and kept in the dark and centrifuged at $1000 \times g$ for $5 \mathrm{~min}$ to remove the leaf debris. Chlorophyll $\mathrm{a}+\mathrm{b}$ content was determined for each sample with a spectrophotometer (DU 730, Beckman Coulter Inc., USA) according to the methods of Graan and Ort (1984).
The soluble sugars of fresh leaf tissue were extracted with boiling ethanol/water and determined by the method of Sharma et al. (1998a), using an ultraviolet spectrophotometer (DU 730, Beckman Coulter Inc., USA). The concentration of soluble sugars was expressed as a percentage of fresh weight (w/w, FW).

The quantitative determination of total free amino acid was carried out by using spectrophotometer method (Rosen, 1957). Free amino acids were extracted from 0.1 g plant samples by homogenizing at $4^{\circ} \mathrm{C}$ in $5 \mathrm{~mL}$ of $80 \%$ (v/v) ethanol, diluted to a volume of $20 \mathrm{~mL}$ with $80 \%$ ethanol, kept in a water bath at $70^{\circ} \mathrm{C}$ for $30 \mathrm{~min}$, and then centrifuged at $12000 \times g$ for $10 \mathrm{~min}$. The supernatants were filtered and then the filtrates were separated by twodimensional paper chromatography (Whatman No. 1) according to Stepka (1957). The paper was loaded with 0.1 $\mathrm{mL}$ of the acetone extract. Phenol:water $(100: 39 \mathrm{v} / \mathrm{v})$ was used as first and butanol: acetic acid: water (100:22:55 $\mathrm{v} / \mathrm{v}$ ) as second solvent. Papers were developed by spraying with $0.5 \%$ ninhydrin in acetone and heating the dry paper at $65-70^{\circ} \mathrm{C}$ for $20 \mathrm{~min}$. Identification of the separated amino acids was done using the reference standard. The spots were eluted with $4 \mathrm{~mL}$ of $75 \% \mathrm{EtOH}$, respectively and then $0.2 \mathrm{~mL}$ eluent was made up to $2 \mathrm{~mL}$ deionized water and $1 \mathrm{~mL}$ ninhydrin solution was added. The absorbance at $570 \mathrm{~nm}$ was measured with a spectrophotometer (DU 730, Beckman Coulter Inc., USA) against a blank containing $2 \mathrm{~mL}$ deionized water and $1 \mathrm{~mL}$ ninhydrin solution. The concentration of each amino acid was determined from each amino acid standard curve. The phenylalanine concentration was estimated with equally handled phenylalanine standards. The total amino acid concentration was the amount of each amino acid concentration.

\section{Extraction andanalysisoftotalpolyphenols, anthocyanins,} and flavonoids

Five gram sample of fresh leaf tissue was frozen with liquid nitrogen, ground into a fine powder, homogenized in $50 \mathrm{~mL}$ of methanol containing $1 \% \mathrm{HCl}$. The solution was sonicated for 20 min with continual $\mathrm{N}_{2}$ gas purging and centrifuged for $15 \mathrm{~min}$ at $12000 \times g$ at $4^{\circ} \mathrm{C}$. The supernatant was filtered through paper filter. The methanol extract was pooled and concentrated. The aqueous residue was extracted with petroleum ether $(3 \times 30 \mathrm{~mL})$, to remove pigments and lipids, and solvent residue was then removed under vacuum. The remaining solution was made up to $25 \mathrm{~mL}$ with methanol, and this solution was analyzed for total polyphenols (TP), total flavonoids (TF), and total anthocyanins (TA). Measurements of TP were carried out according to Arnous et al. (2001) by using the Folin-Ciocalteu reagent and the values were read at 675 $\mathrm{nm}$. Gallic acid was used as the reference standard and results were expressed as $\mathrm{mg}$ gallic acid equivalents (GAE) $100 \mathrm{~g}^{-1}$ fresh weight (FW).

The flavonoid contents of Ginkgo biloba leaves grown in various concentrations of CCC were measured as de- 
scribed by Xu et al. (2011). Briefly, one milliliter aliquot of extract, appropriately diluted, was mixed with $0.4 \mathrm{~mL}$ distilled water in a $1.5 \mathrm{~mL}$ micro centrifuge tube. Thirty microliters of $5 \% \mathrm{NaNO}_{2}$ solution were added and the solution was thoroughly mixed. Five minutes later, thirty microlitre of $10 \% \mathrm{AlCl}_{3}$ was added and the mixture was left to stand for $5 \mathrm{~min}$. Then, two hundred microlitre 1 $\mathrm{M} \mathrm{Na}_{2} \mathrm{CO}_{3}$ and $0.24 \mathrm{~mL}$ distilled water were added. After mixing the solution thoroughly, the absorbance was measured immediately at $510 \mathrm{~nm}$ using a microplate spectrophotometer. Total flavonoids content was calculated from a calibration curve using rutin as a standard and expressed as milligrams of rutin equivalents (RE) $100 \mathrm{~g}^{-1} \mathrm{FW}$.

TA was determined as described by Pirie and Mullins (1976) with minor modification. An aliquot of extract (5 $\mathrm{mL}$ ) was combined with ethanolic $\mathrm{HCl}$ solution $(0.25 \mathrm{M})$ to give a 1:10 dilution. After thorough mixing, the absorbance at $520 \mathrm{~nm}$ was read after $5 \mathrm{~min}$. Total anthocyanin contents was determined as milligrams of cyanin (cyanidin 3-O-glucoside) equivalents $100 \mathrm{~g}^{-1} \mathrm{FW}$.

\section{Determination of enzyme activity}

Enzyme extracts were prepared as described by Xu et al. (2011). Protein was determined according to the Bradford method using BSA as a standard (Bradford, 1976). Phenylalanine ammonia-lyase (PAL) (E.C. 4.3.1.5) activity was measured as described by Solecka and Kacperska (2003). One unit of enzyme activity equaled the amount of PAL that produced $1 \mathrm{nmol}$ of cinnamic acid in $1 \mathrm{~h}$. Chalcone synthase (CHS) (E.C. 2.3.1.74) activity was measured according to Xu et al. (2007). Chalcone isomerase (CHI) (E.C. 5.5.1.6) activity was measured with the method of Li et al. (2006). CHS and CHI activities were both expressed as unit $\mathrm{mg}^{-1}$ protein.

\section{Statistical analysis}

Data were statistically analyzed as a completely randomized design with each treatment replicated six times by analysis of variance (ANOVA) using Data Processing System (DPS, Zhejiang University, Hangzhou, China). Appropriate standard errors of means (SE) were calculated. Duncan's multiple-range test was applied to compare measured parameters from plants that had experienced different treatments.

\section{Results}

Effect of CCC on leaf photosynthetic rates, Chlorophyll $a+b$, soluble sugar, total amino acids and phenylalnine contents

The changes in photosynthetic active of plants induced by spraying CCC were observed. Treatments with $0.5,1.0$ and $2.0 \mathrm{~g} \mathrm{~L}^{-1} \mathrm{CCC}$ resulted in an increase of $1.92,29.12$ and $48.85 \%$ in net photosynthesis rate $\left(P_{n}\right)$ compared with the control, respectively. Treatments with 0.5 and $2.0 \mathrm{~g} \mathrm{~L}^{-1}$ CCC resulted in an increase of 20 and $40 \%$ in stomatal conductance $\left(G_{s}\right)$ compared with the control, respectively; while treatment with $1.0 \mathrm{~g} \mathrm{l}^{-1}$ CCC decreased the $G$ by $10 \%$ relative to the control. Treatments with 0.5 , 1.0 and $2.0 \mathrm{~g} \mathrm{l}^{-1} \mathrm{CCC}$ resulted in an increase in intercellular $\mathrm{CO}_{2}\left(C_{i}\right)$ of $11.52,23.67$ and $9.93 \%$ in ginkgo leaves, respectively. Treatments with $0.5,1.0$ and $2.0 \mathrm{~g} \mathrm{l}^{-1} \mathrm{CCC}$ increased transpiration rate $\left(T_{r}\right)$ by $8.33,18.33$, and $33.33 \%$, respectively. The $P_{n}, G_{s}, C_{i}$, and $T_{r}$ of leaves were significantly different from each other (Tab. 1).

Spraying CCC not only improved the photosynthetic parameters of ginkgo leaves but also affect the contents of chlorophyll $\mathrm{a}+\mathrm{b}$, soluble sugar, total amino acids and phenylalnine in ginkgo leaves. The effect of $2.0 \mathrm{~g} \mathrm{l}^{-1} \mathrm{CCC}$ was more pronounced on chlorophyll $\mathrm{a}+\mathrm{b}$, soluble sugar, and total amino acids than other treatments, whereas 1.0 $\mathrm{g} \mathrm{l}^{-1} \mathrm{CCC}$ was the most effective on phenylalnine content (Tab. 2). With 0.5 and $1.0 \mathrm{~g} \mathrm{l}^{-1} \mathrm{CCC}$ treatment, the chlorophyll $a+b$ contents were less in ginkgo leaves than the control.

Tab. 1. Effects of CCC on the photosynthetic parameters in ginkgo leaves

\begin{tabular}{ccccc}
\hline CCC treatment & $P_{n}\left(\mathrm{CO}_{2} \mu \mathrm{mol} \mathrm{m} \mathrm{s}^{-1}\right)$ & $G_{s}\left(\mathrm{H}_{2} \mathrm{O} \mathrm{mol} \mathrm{m} \mathrm{s}^{-1}\right)$ & $C_{i}\left(\mathrm{CO}_{2} \mu \mathrm{ll}^{-1}\right)$ & $T_{r}\left(\mathrm{H}_{2} \mathrm{O} \mathrm{mmol} \mathrm{m}^{-2} \mathrm{~s}^{-1}\right)$ \\
\hline $0($ Control $)$ & $10.44 \pm 0.61 \mathrm{c}$ & $0.20 \pm 0.01 \mathrm{c}$ & $276.75 \pm 12.70 \mathrm{~b}$ & $1.20 \pm 0.06 \mathrm{c}$ \\
$0.5 \mathrm{gl}^{-1}$ & $10.64 \pm 0.83 \mathrm{c}$ & $0.24 \pm 0.02 \mathrm{~b}$ & $308.62 \pm 33.02 \mathrm{~b}$ & $1.30 \pm 0.10 \mathrm{c}$ \\
$1.0 \mathrm{gl}^{-1}$ & $13.48 \pm 1.41 \mathrm{~b}$ & $0.18 \pm 0.03 \mathrm{c}$ & $342.25 \pm 19.36 \mathrm{a}$ & $1.42 \pm 0.04 \mathrm{~b}$ \\
$2.0 \mathrm{gl}^{-1}$ & $15.54 \pm 1.13 \mathrm{a}$ & $0.28 \pm 0.02 \mathrm{a}$ & $304.23 \pm 12.25 \mathrm{~b}$ & $1.60 \pm 0.04 \mathrm{a}$ \\
\hline
\end{tabular}

$P_{n}, G_{s}, C_{i}$, and $T_{r}$ represent net photosynthetic rate, stomatal conductance, intercellular $\mathrm{CO}_{2}$ concentration, and transpiration rate, respectively. Values are mean \pm standard error (SE) of six replications. Different letters within the same column indicate significant differences between treatments according to Duncan's multiple range test at $p<0.05$ level

Tab. 2. Effect of CCC on the contents of Chlorophyll $a+b$, soluble sugar, total amino acids, phenylalnine in ginkgo leaves

\begin{tabular}{ccccc}
\hline CCC treatment & $\begin{array}{c}\text { Chlorophyll } \mathrm{a}+\mathrm{b} \\
\left(\mathrm{mg} \mathrm{g}^{-1} \mathrm{FW}\right)\end{array}$ & $\begin{array}{c}\text { Soluble sugar } \\
\left(\mathrm{mg} \mathrm{g}^{-1} \mathrm{FW}\right)\end{array}$ & $\begin{array}{c}\text { Total amino acids } \\
\left(\text { ug g }^{-1} \mathrm{FW}\right)\end{array}$ & $\begin{array}{c}\text { Phenylalnine } \\
\left(\mathrm{ug} \mathrm{g}^{-1} \mathrm{FW}\right)\end{array}$ \\
\hline $0($ Control $)$ & $1.47 \pm 0.06 \mathrm{~b}$ & $11.66 \pm 0.65 \mathrm{c}$ & $8.81 \pm 0.31 \mathrm{~d}$ & $0.16 \pm 0.01 \mathrm{~d}$ \\
$0.5 \mathrm{gl}^{-1}$ & $1.39 \pm 0.09 \mathrm{~b}$ & $12.46 \pm 0.36$ & $10.95 \pm 0.52 \mathrm{c}$ & $0.22 \pm 0.01 \mathrm{c}$ \\
$1.0 \mathrm{gl}^{-1}$ & $1.46 \pm 0.04 \mathrm{~b}$ & $13.36 \pm 0.23 \mathrm{~b}$ & $16.99 \pm 1.04 \mathrm{~b}$ & $0.36 \pm 0.03 \mathrm{a}$ \\
\hline $2.0 \mathrm{gl}^{-1}$ & $1.79 \pm 0.02 \mathrm{a}$ & $14.28 \pm 0.40 \mathrm{a}$ & $21.47 \pm 0.89 \mathrm{a}$ & $0.31 \pm 0.01 \mathrm{~b}$ \\
\hline
\end{tabular}

Values are mean \pm standard error (SE) of six replications. Different letters within the same column indicate significant differences between treatments according to Duncan's multiple range test at $p<0.05$ level 
100

Soluble sugar contents in all leaves, regardless of treatment, increased gradually (Tab. 2). The sugar contents were significantly $(p<0.05)$ higher in leaves treated with $2.0 \mathrm{~g}^{-1} \mathrm{CCC}$ than in the control. Sugar contents in leaves treated with 0.5 and $1.0 \mathrm{~g} \mathrm{l}^{-1} \mathrm{CCC}$ conditions were $6.86 \%$ and $14.58 \%$, respectively, higher than control.

Enhancement of total amino acids and phenylalnine after CCC treatments (Tab. 2) was observed in leaves. The total amino acids were increased in leaves by $24.92,92.85$, and $143.7 \%$ at $0.5,1.0$, and $2.0 \mathrm{~g} \mathrm{l}^{-1}$ of CCC treatment compared with the control, respectively. Treatments with $0.5,1.0$ and $2.0 \mathrm{~g} \mathrm{~L}^{-1} \mathrm{CCC}$ resulted in an increase of 37.5, 125 and $93.75 \%$ in phenylanine contents compared with the control, respectively.

\section{Effect of CCC on PAL, CHS, and CHI activities}

Changes in three enzymes activities are shown in Tab. 3. Under CCC treatment the activity of PAL in leaves showed an increase compared to control, with the $1.0 \mathrm{~g}$ $1^{-1}$ CCC treatment the activity of PAL was significantly higher (70.88\% higher) than control, but treated with 0.5 and $2.0 \mathrm{gl}^{-1} \mathrm{CCC}$ were not significant $(p>0.05)$. The CHS activity of the leaves treated with 0.5 and $2.0 \mathrm{gl}^{-1} \mathrm{CCC}$ was significantly higher $(p<0.05)$ than control, while treated with $1.0 \mathrm{~g} \mathrm{l}^{-1}$ CCC was significantly lower (1.99\% lower) than control. CHI activity of leaves increased gradually under the CCC treatment. CHS activity was significantly $(p<0.05)$ enhanced (127.16\% higher) above the control level by CCC treatment at $2.0 \mathrm{~g} \mathrm{l}^{-1}$. The CHI activities of the leaves treated with 0.5 and $1.0 \mathrm{~g} \mathrm{l}^{-1}$ CCC were $67.65 \%$ and $99.81 \%$ higher, respectively, than control (Tab. 3).

\section{Effect of CCC on total polyphenols, flavonoids and} anthocyanins

The contents of TP, TF and TA showed an increase in ginkgo leaves under CCC treatment. A gradual increase in TP, TF and TA in CCC-treated leaves from treatment with 0.5 and $1.0 \mathrm{~g} \mathrm{l}^{-1} \mathrm{CCC}$. The TP, TF and TA contents in CCC treated leaves at $2.0 \mathrm{~g} \mathrm{l}^{-1}$ was lower than CCC treated leaves at $1.0 \mathrm{~g} \mathrm{l}^{-1} \mathrm{CCC}$, but still higher than control. Furthermore, the TP, TF and TA contents of leaves at $1.0 \mathrm{~g} \mathrm{l}^{-1}$ and $2.0 \mathrm{~g} \mathrm{l}^{-1} \mathrm{CCC}$ application were significantly higher $(p<0.05)$ than their corresponding control, The TP contents were significantly increased $24.46 \%$ and $20.7 \%$, respectively, and TF contents were significantly increased $23.37 \%$ and $18.46 \%$ respectively, while TA contents were significantly increased $16.67 \%$ and $13.89 \%$, respectively (Tab. 4).

\section{Discussion}

CCC has been reported to benefit photosynthesis by increasing chlorophyll content in potato (Wang et al., 2009), onion (Miroshnichenko and Manankov, 1991), wheat (Stahli et al., 1995) and sunflower (Kumari and Bharti, 1992). Our research found that photosynthetic rates in ginkgo leaves could be significantly enhanced by foliar application of CCC (Tab. 1). The enhanced photosynthetic capacity might have been ascribed to the increased leaf thickness, leaf photosynthetic pigment contents, and stomata activity induced by CCC treatments (Tezuka et al., 1989; Wang et al., 2009).

Our data also showed that the increased chlorophyll $\mathrm{a}+\mathrm{b}$ contents in ginkgo leaves in the CCC-treated plants, coincided with an increase in the photosynthetic capacity as indicated by the higher $P_{n}, G_{s}, C_{i}$, and $T_{r}$ in those plants (Tab. 1 and 2). The increase in chlorophyll $\mathrm{a}+\mathrm{b}$ might be associated with the increases in anthocyanin and flavonoid contents, as a positive relationship was noted among chlorophyll, anthocyanin, and flavonoid contents (Xu et al., 2011).

In the present experiment, CCC treatments enhanced leaf soluble sugar content, which is in agreement with earlier reports (Sharma et al., 1998a; Wang and Xiao, 2009),

Tab. 3. Effects of CCC on the activities of PAL, CHS and CHI of ginkgo leaves

\begin{tabular}{cccc}
\hline CCC treatment & PAL $\left(\mathrm{U} \mathrm{mg}^{-1}\right.$ protein $)$ & CHS(U mg ${ }^{-1}$ protein $)$ & CHI $\left(\mathrm{U} \mathrm{mg}^{-1}\right.$ protein $)$ \\
\hline 0 (Control) & $227.29 \pm 7.47 \mathrm{~d}$ & $16.61 \pm 1.98 \mathrm{a}$ & $42.63 \pm 1.17 \mathrm{~d}$ \\
$0.5 \mathrm{gl}^{-1}$ & $284.68 \pm 8.76 \mathrm{c}$ & $16.88 \pm 0.99 \mathrm{a}$ & $71.47 \pm 3.86 \mathrm{c}$ \\
$1.0 \mathrm{~g} \mathrm{l}^{-1}$ & $388.39 \pm 6.66 \mathrm{a}$ & $16.28 \pm 2.30 \mathrm{a}$ & $85.16 \pm 4.52 \mathrm{~b}$ \\
$2.0 \mathrm{~g} \mathrm{l}^{-1}$ & $358.90 \pm 17.59 \mathrm{~b}$ & $16.88 \pm 0.60 \mathrm{a}$ & $96.84 \pm 1.80 \mathrm{a}$ \\
\hline
\end{tabular}

Values are mean \pm standard error (SE) of six replications. Different letters within the same column indicate significant differences between treatments according to Duncan's multiple range test at $p<0.05$ level

Tab. 4. Effects of CCC on the contents of total polyphenols, flavonoids and anthocyanins in ginkgo leaves

\begin{tabular}{|c|c|c|c|}
\hline CCC treatment & $\begin{array}{l}\text { Total polyphenols } \\
\left(\mathrm{mg} 100 \mathrm{~g}^{-1} \mathrm{FW}\right)\end{array}$ & 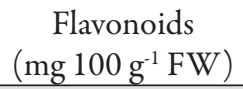 & 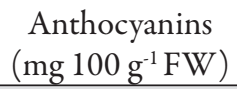 \\
\hline 0 (Control) & $220.99 \pm 12.92 c$ & $149.79 \pm 6.32 \mathrm{~b}$ & $0.36 \pm 0.02 b$ \\
\hline $0.5 \mathrm{gl}^{-1}$ & $243.13 \pm 6.77 b$ & $157.95 \pm 9.91 \mathrm{~b}$ & $0.37 \pm 0.02 \mathrm{~b}$ \\
\hline $1.0 \mathrm{gl}^{-1}$ & $275.05 \pm 17.35 a$ & $184.79 \pm 5.29 a$ & $0.42 \pm 0.02 \mathrm{a}$ \\
\hline $2.0 \mathrm{gl}^{-1}$ & $266.74 \pm 5.27 \mathrm{a}$ & $177.44 \pm 3.83 a$ & $0.41 \pm 0.02 \mathrm{a}$ \\
\hline
\end{tabular}

Values are mean \pm standard error (SE) of six replications. Different letters within the same column indicate significant differences between treatments according to Duncan's multiple range test at $p<0.05$ level 
where addition of CCC increased the carbohydrate in the tissues in potato. However, our result is not in agreement with the reports of oat caryopses (Foley, 1987) and radish seedlings (Jain and Guruprasad, 1989), where the carbohydrate decreased after CCC treatment. This promotive effect of CCC on soluble sugar contents was likely resulted from the increase in photosynthetic activity of the CCC treated plants due to a higher chlorophyll content of the leaves (Sharma et al., 1998b).

Significant enhancement in the contents of total amino acids and phenylalnine were observed in response to CCC in the treated ginkgo leaves (Tab. 2), and similar with the literature (Ibrahim and Nermin, 2001) that the protein and amino acid contents were higher in seedlings of CCC treated maize seeds than those of untreated ones. The synthesis of amino acids is coupled to uptake of nitrogen and carbon, and sugars produced by photosynthesis are used as sources of carbon and energy for the synthesis of amino acids (Miyashita and Miyazaki, 1992). Therefore, the increase in total amino acids might be associated with the increases in soluble sugar contents, as a positive relationship was noted among chlorophyll, anthocyanin, and flavonoid contents. That is, the increased net photosynthesis may have produced carbohydrate in excess to what is need for ginkgo growth because of the CCC application.

This study results showed phenylalnine content increased in the CCC-treated ginkgo leaves. A similar conclusion has been reached in buckwheat seedlings (Margna et al., 1969), where CCC increased the level of phenylalanine. Jain and Guruprasad (1989) found that the CCC mediated promotion of anthocyanin synthesis with or without $\mathrm{GA}_{3}$ supplied can be correlated with an increase in the total free amino acids, in particular phenylalanine. External application of phenylalanine along with CCC further enhanced the synthesis of anthocyanin. In the CCC-treated ginkgo leaves, total anthocyanins contents were also increased. In contrast to our results, phenylalanine did not promote CCC-induced anthocyanin synthesis in red cabbage and spiderwort tissues (Grebinskii and Khmil, 1980). This difference may be due to the presence of phenylalanine in saturating levels in cabbage and spiderwort tissues after application of CCC.

Polyphenols, flavonoids, and anthocyanins are all involved in the quality characteristics of ginkgo leaves and their processed products, like GBE761 (van Beek, 2002). The present study showed notable increase in total polyphenols, flavonoids, and anthocyanins contents following CCC-treatment. CCC treatments also significantly induced the activities of PAL, CHS, and CHI in a concentration-dependent manner in ginkgo leaves. Recent findings demonstrated that PAL, CHS and CHI were both key regulatory enzymes in flavonoid biosynthesis in G. biloba leaves (Cheng et al., 2011; Xu et al., 2007, 2008) and observed that CCC could induce the transcription of chalcone isomerase gene (GbCHI) in ginkgo leaves (Cheng et al., 2011). The transcript levels of several genes encod- ing the enzymes involved in flavonoid and anthocyanin biosyntheses, such as PAL, CHS, and CHI, are positively correlated with the accumulation of flavonoids and anthocyanins (Fischer et al., 2007; Jaakola et al., 2002).

Total polyphenol, flavonoid, and anthocyanin contents have a positive relationship with the activities of PAL, CHS and CHI in many plants (Ju et al., 1995; Mato et al., 2000; Obinata et al., 2003). Our recently work also demonstrated that CHS and PAL were two key enzymes involved in flavonoid biosynthetic pathway in G. biloba (Cheng et al., 2012). For these reasons, increase in the total polyphenol, flavonoid, and anthocyanin contents have been assumed to be due to enhanced PAL, CHS and CHI activities as a result of CCC treatment. In addition, one recent report suggests that lemon balm leaves were exposed to high levels of sucrose, and in response, the anthocyanins and flavonoids accumulated (Hossain et al., 2009). Sugarinduced anthocyanin accumulation has been reported in other plant species (Nagira et al., 2006; Solfanelli et al., 2006). The accumulation of total polyphenol, flavonoid, and anthocyanin contents in CCC-treated ginkgo leaves might also has a few relationships with the extra soluble sugar content, which was enhanced by CCC treatment. Our present data indicated $1.0 \mathrm{~g} \mathrm{I}^{-1} \mathrm{CCC}$ application has most promotive effects on total polyphenol, flavonoid, and anthocyanin contents and on PAL, CHS and CHI activities.

\section{Conclusions}

From present studies it may be concluded that CCC at concentrations of $1.0 \mathrm{~g} \mathrm{l}^{-1}$ and $2.0 \mathrm{~g} \mathrm{l}^{-1}$ greatly promotes chlorophyll, soluble sugar content, total amino acids and phenylanine, which are benefit for the accumulation of total polyphenol, flavonoid and anthocyanin contents in ginkgo leaves. Total polyphenol, flavonoid, and anthocyanin contents and PAL, CHS and $\mathrm{CHI}$ activities are much more induced by $1.0 \mathrm{gl}^{-1} \mathrm{CCC}$ in ginkgo leaves. It should be suggested that CCC was an appropriate choice for treating ginkgo plants with the objective of increasing the production of flavonoids.

\section{Acknowledgments}

This work was supported by National Natural Science Foundation of China (No. 31000904) and Key Project of Chinese Ministry of Education (212112).

\section{References}

Adamski JM, Peters JA, Danielosk R, Bacarin MA (2011). Excess iron-induced changes in the photosynthetic characteristics of sweet potato. Journal of Plant Physiology 168:20562062.

Arnous A, Makris DP, Kefalas P (2001). Effect of principal polyphenolic components in relation to antioxidant characteristics of aged red wines. J Agric Food Chem 49:5736-5742. 
102

Bradford MM (1976). A rapid and sensitive method for the quantitation of microgram quantities of protein utilizing the principle of protein-dye binding. Anal Biochem 72:248254.

Cheng H, Li LL, Cheng SY, Cao FL, Wang Y, Yuan HH (2011). Molecular cloning and function assay of a chalcone isomearse gene ( $G b C H I)$ from Ginkgo biloba. Plant Cell Rep 30:49-62.

Cheng SY, Wang Y, Fei YJ, Zhu GC (2004). Studies on the effects of different treatments on flavonoids contents in Ginkgo biloba leaves and their regulating mechanism. J Fruit Sci 21:116-119.

Cheng SY, Wang Y, Li JK, Tao ZY (2001). Study on the relationship between the flavonoids and pigments in Ginkgo biloba leaf. Sci Silvae Sin 37:31-34.

Cheng SY, Xu F, Wang Y (2009). Advances in the study of flavonoids in Ginkgo biloba leaves. J Med Plants Res 3:12481252.

Cheng S, Xu F, Li L, Cheng H, Zhang W (2012). Seasonal pattern of flavonoid content and related enzyme activities in leaves of Ginkgo biloba L. Not Bot Horti Agrobo 40:98-106

Ding XP, Jin Q, Chang YX, Mu LL, Zhu DN, Yu BY (2009). Qualitycontrol of flavonoids in Ginkgo biloba leaves by high-performance liquid chromatography with diode array detection and on-line radical scavenging activity detection. J Chromatography A 1216:2204-2210.

Fischer TC, Gosch C, Pfeiffer J, Halbwirth H, Halle C, Stich K, Forkmann G (2007). Flavonoid genes of pear (Pyrus communis). Trees-Struct Funct 21:521-529.

Foley ME (1987). Effect of wounding on primary dormancy in wild oat (Avena fatua) caryopses. Weed Sci 35:180-184.

Graan T, Ort DR (1984). Quantitation of the rapid electron donors to P 700, the functional plastoquinone pool and the ratio of the photosystems in spinach chloroplast. J Biol Chem 259:14003-14010.

Grebinskii SO, Khmil MV (1980). Effect of CCC on biosynthesis of anthocyanin in leaves of red cabbage and spiderwort. Fiziol Biokhim Kult Rast 12:409-412.

Grossmann K (2010). Plant growth retardants as tools in physiological research. Physiol Plant 78:640-648.

Guruprasad KN, Laloraya MM (1980). Effect of pigment precursors on the inhibition of anthocyanin biosynthesis by GA and ABA. Plant Sci Lett 19:73-79.

Hossain MA, Kim S, Kim KH, Lee SJ (2009). Flavonoid compounds are enriched in lemon balm (Melissa officinalis) leaves by a high level of sucrose and confer increased antioxidant activity. Hortscience 44:1907-1913.

Ibrahim MZ, Nermin AE (2001). Response of two differentially drought tolerant varieties of maize to drought stress. Pak J Biol Sci 4:779-784.

Iwashita KA, Kobori MB, Yamaki KB, Tsushida TB (2000). Flavonoids inhibit cell growth and induce apoptosis in B16 Melanoma 4A5 cells. Biosci Biotechnol Biochem 64:1813-
1820.

Jaakola L, Maatta K, Pirttila AM, Torronen R, Karenlampi S, Hohtola A (2002). Expression of genes involved in anthocyanin biosynthesis in relation to anthocyanin, proanthocyanindin, and flavonol levels during bilberry fruit development. Plant Physiol 130:729-739.

Jain VK, Guruprasad KN (1989). Effect of chlorocholine chloride and gibberellic acid on the anthocyanin synthesis in radish seedlings. Physiol Plant 75:233-236.

Ju Z, Liu C, Yuan Y (1995). Activities of chalcone synthase and UDPGal: flavonoid-3-o- glycosyltransferase in relation to anthocyanin synthesis in apple. Sci Hortic 63:175-185.

Kawaii S, Tomono Y, Katase E, Ogawa K, Yano M (1999). Antiproliferative activity of flavonoids on several cancer cell lines. Biosci Biotechnol Biochem 63:896-899.

Kumari S, Bharti S (1992). Effect of CCC and FAP on photosynthesis in sunflower under simulated drought conditions. Haryana Agric Univ J Res 22:206-213.

Li F, Jin Z, Qu W, Zhao D, Ma F (2006). Cloning of a cDNA encoding the Saussurea medusa chalcone isomerase and its expression in transgenic tobacco. Plant Physiol Biochem 44:455-461.

Margna U, Margna E, Otter M (1969). The effect of some antibiotics on the formation of anthocyanin and rutin in buckwheat seedlings hypocotyls. Esti Nsv Teadjste Akadeemia Tolmetised SVIII Koide Biologia 3:291-299.

Mato M, Onozaki T, Ozeki Y, Higeta D, Itoh Y, Yoshimoto Y, Ikeda H, Yoshida H, Shibata M (2000). Flavonoid biosynthesis in white-flowered Sim carnations (Dianthus caryophyllus). Sci Hortic 84:333-347.

Miroshnichenko TA, Manankov MI (1991). Effect of gibberellin and chlorocholine chloride on the pigment complex of onion. Fiziol Biokhim Kult Rast 23:452-455.

Miyashita S, Miyazaki T (1992). Seasonal changes in neutral sugars and amino acids of particulate matter in Lake Nakanuma, Japan. Hydrobiologia 245:95-104.

Nagira Y, Ikegami K, Koshiba T, Ozeki Y (2006). Effect of ABA upon anthocyanin synthesis in regenerated torenia shoots. J Plant Res 119:137-144.

Obinata N, Yamakawa T, Takamiya M, Tanaka N, Ishimaru K, Kodama T (2003). Effects of salicylic acid on the production of procyanidin and anthocyanin in cultured grape cells. Plant Biotechnol 20:105-111.

Pirie A, Mullins MG (1976). Changes in anthocyanin and phenolics content of grapevine Leaf and fruit tissues treated with sucrose, nitrate, and abscisic Acid. Plant Physiol 58:468-472.

Rosen $H$ (1957). A modified ninhydrin colorimetic analysis of amino acids. Arch Biochem Biophys 67:10-15.

Sharma N, Kaur N, Gupta AK (1998a). Effect of chlorocholine chloride sprays on the carbohydrate composition and activities of sucrose metabolising enzymes in potato. Plant Growth Regul 26:97-103. 
Sharma N, Kaur N, Gupta AK (1998b). Effects of gibberellic acid and chlorocholin chloride on tuberisation and growth of potato (Solanum tuberosum L.). J Sci Food Agric 78:466470.

Solecka D, Kacperska A (2003). Phenylpropanoid deficiency affects the course of plant acclimation to cold. Physiol Plant 119:253-262.

Solfanelli C, Poggi A, Loreti E, Alpi A, Perata P (2006). Sucrosespecific induction of the anthocyanin biosynthetic pathway in Arabidopsis. Plant Physiol 140:637-646.

Stahli D, Perissin-Tabert D, Blouet A, Guckert A (1995). Contribution of the wheat (Triticum aestivum L.) flag leaf to grain yield in response to plant growth regulators. Plant Growth Regul 16:293-297.

Stepka W (1957). Identification of amino acids by paper chromatography. Methods in Enzymology 3:504-528.

Tezuka T, Takahara C, Yamamoto Y (1989). Aspects regarding the action of CCC in hollyhock plants. J Exp Bot 40:689692.

van Beek TA (2002). Chemical analysis of Ginkgo biloba leaves and extracts. J Chromatogr A 967:21-55.

Wang H, Li H, Liu F, Xiao L (2009). Chlorocholine chloride application effects on photosynthetic capacity and photoassimilates partitioning in potato (Solanum tuberosum L.). Sci Hortic 119:113-116.
103

Wang H, Xiao L (2009). Effects of chlorocholine chloride on phytohormones and photosynthetic characteristic in potato. J Plant Growth Regul 28:21-27

Wang H, Xiao L, Tong J, Liu F (2010). Foliar application of chlorocholine chloride improves leaf mineral nutrition, antioxidant enzyme activity, and tuber yield of potato (Solanum tuberosum L.). Sci Hortic 125:521-523.

Wang Y, Li LL, Xu F, Liu WH, Cheng SY (2007). Effects of some metal ions on phenylalanine ammonia-lyase activities and flavonoids content of Ginkgo biloba leaves in the potted orchard. J Nanjing Forest Univ 31:68-72.

Winkel-Shirley B (2002). Biosynthesis of flavonoids and effects of stress. Curr Opin Plant Biol 5:218-233.

Xu F, Cai R, Cheng SH, Du H, Wang Y, Cheng SY (2008). Molecular cloning, characterizaion and expression of phenylalanine ammonia-lyase gene from Ginkgo biloba. Afr J Biotechnol 7:721-729.

Xu F, Cheng SY, Cheng SH, Wang Y, Du HW (2007). Time course of expression of chalcone synthase gene in Ginkgo biloba. J Plant Physiol Mol Biol 33:309-317.

Xu F, Cheng SY, Zhu J, Zhang WW, Wang Y (2011). Effects of 5-aminolevulinic acid on chlorophyll, photosynthesis, soluble sugar and flavonoids of Ginkgo biloba. Not Bot Horti Agrobo 39:41-47. 